\title{
A ETNOGRAFIA E SUAS CONTRIBUIÇÕES PARA O DESENVOLVIMENTO DE UMA PESQUISA NO CONTEXTO DE ENSINO DA PEDAGOGIA DA ALTERNÂNCIA
}

\author{
ETHNOGRAPHY AND ITS CONTRIBUTIONS TO THE \\ DEVELOPMENT OF A RESEARCH IN THE TEACHING \\ CONTEXT OF THE PEDAGOGY OF ALTERNATION
}

\author{
Cícero da Silva* \\ Adair Vieira Gonçalves **
}

\begin{abstract}
RESUMO
Neste artigo, analisam-se as contribuições advindas da etnografia para o desenvolvimento de uma pesquisa em uma Escola Família Agrícola (EFA). Por ser uma pesquisa de natureza etnográfica, adota-se a abordagem qualitativa e interpretativa na análise dos dados, pois o foco são práticas e eventos de letramento mediados pelos Instrumentos Pedagógicos da Pedagogia da Alternância (PA). Os dados foram gerados em 2014 e são constituídos por: material audiovisual, diários de campo, documentos da escola-campo, fotografias e textos de (16) exemplares do gênero Caderno da Realidade. Considerando a proposta didático-pedagógica do contexto educativo da PA assumida pela escola-campo e o trabalho dos monitores, o estudo mostra que a formação dos estudantes possibilita desenvolver capacidades de linguagem a partir dos usos sociais da escrita na escola e na comunidade.

Palavras-chave: Alternância; Instrumentos Pedagógicos; letramento.
\end{abstract}

\section{ABSTRACT}

In this paper, we analyse the ethnography contributions to the development of a research in a school named Escola Familia Agrícola (EFA). As it is an ethnographic research, we have been adopted the qualitative and interpretative approach in data analysis, because the study focus are the literacy practices and events mediated by the pedagogical tools of the Pedagogy of Alternation. The data were generated in 2014 and consist of: audio-visual material, field notes, school documents, photographs and texts of (16) the genre Notebook of Reality. Considering the didactic-pedagogical proposal of the teaching context of the Pedagogy of Alternation had assumed by the school and the teachers' work, the research results have revealed that the students training makes it possible to develop language skills from the social uses of writing at school and in the community.

Keywords: Alternation; Pedagogical tools; literacy.

\footnotetext{
* Universidade Federal do Tocantins, Tocantinópolis, TO. Brasil. cicolinas@yahoo.com.br ** Universidade Federal da Grande Dourados, Dourados, MS. Brasil. adairgoncalves@uol.com.br
} 


\section{PALAVRAS INICIAIS}

O letramento, pelas dimensões sociais e culturais que apresenta envolvendo os atores humanos, constitui um objeto de estudo importante para a Pedagogia da Alternância (PA) e a Educação do Campo. Entretanto, como aponta Silva (2018), ainda é reduzido o número de estudos desenvolvidos a respeito do tema em escolas situadas no meio rural brasileiro. Considerando que esta pesquisa ${ }^{1}$ integra uma investigação mais ampla cujo foco são práticas e eventos de letramento ${ }^{2}$ mediados pelos Instrumentos Pedagógicos (IP) da Pedagogia da Alternância (PA), especificamente, o objetivo neste artigo é estabelecer relação estreita entre a etnografia e suas contribuições para o desenvolvimento da pesquisa na área de estudos da linguagem, focalizando práticas de letramento orientadas pelos princípios da alternância em uma Escola Família Agrícola (EFA) brasileira.

Para investigar como e que práticas de letramento são mobilizadas/ desenvolvidas na alternância, sobretudo durante o estudo dos temas dos Planos de Estudo (PE) para elaboração do gênero Caderno da Realidade (CR), realizamos um estudo etnográfico em uma Escola Família Agrícola (EFA), situada no município de Colinas do Tocantins, estado do Tocantins. Esta pesquisa, desenvolvida em um período longitudinal em 2014, envolveu a participação direta e indireta de 09 (nove) monitores ${ }^{3}$ e 19 (dezenove) alunos colaboradores da instituição na execução dos (08) temas dos $\mathrm{PE}$, na turma do $1^{\mathrm{O}}$ ano do curso Técnico em Agropecuária Integrado ao Ensino Médio.

1. Esta pesquisa foi realizada no âmbito do projeto "Caderno da Realidade na Pedagogia da Alternância: um instrumento pedagógico mediador do letramento" (PROPESQ/UFT no TO3\#001/2015) e contribui para as atividades científicas do Grupo de Estudos e Pesquisas em Educação do Campo - GEPEC (UFT/CNPq).

2. Com base em Street (2014), podemos afirmar que eventos e práticas de letramento não constituem o mesmo elemento, mas caminham lado a lado. Isso porque "O conceito de 'práticas de letramento" se coloca num nível mais alto de abstração e se refere igualmente ao comportamento e às conceitualizações sociais e culturais que conferem sentido aos usos da leitura e/ou da escrita. As práticas de letramento incorporam não só os 'eventos de letramento', como ocasiões empíricas às quais o letramento é essencial, mas também modelos populares desses eventos e as preconcepções ideológicas que os sustentam" (STREET, 2014, p. 18). Conforme a esfera social de uso da linguagem, serão empreendidos diferentes eventos e práticas de letramento.

3. Nas experiências educativas orientadas pela PA, o professor é denominado ou conhecido como monitor. Em outros termos, "o professor é chamado de monitor para significar que seu papel vai além da docência implicando o acompanhamento do aluno não apenas em suas atividades escolares, mas também em sua vida social e profissional" (NOSELLA, 2014, p. 30). Assim, o 'monitor' não é o 'detentor do conhecimento', mas aquele que acompanha, guia, orienta os estudantes em direção às fontes de conhecimento, aquele que facilita a aprendizagem. Além de exercer as atribuições pedagógicas de professor, esse profissional também executa outras atividades (inclusive, administrativas) em um CEFFA (GIMONET, 2007). Por isso, ao longo deste trabalho adotaremos o termo monitor para dirigirmo-nos ao professor. 
Os registros deste estudo são constituídos por material audiovisual - como gravações das interações em sala de aula e de atividades desenvolvidas pelos estudantes nas comunidades, diários de campo do pesquisador, documentos da escolacampo, registros fotográficos de atividades, espaços e objetos, além de textos de (16) exemplares do Caderno da Realidade, um dos instrumentos didático-pedagógicos das unidades de ensino que adotam a PA, produzidos no ano letivo de 2014 por alunos colaboradores do $1^{\circ}$ ano do Ensino Médio da escola focalizada.

Para a consecução desta pesquisa, este artigo está estruturado em duas partes principais. A primeira traz o referencial teórico que alicerça a pesquisa. $\mathrm{Na}$ segunda parte, além da caracterização e contribuição da etnografia para o estudo, apresentamos alguns dados da pesquisa, bem como breves considerações a respeito dos resultados.

\section{A ALTERNÂNCIA E SEUS INSTRUMENTOS PEDAGÓGICOS}

A Pedagogia da Alternância (PA) é um sistema educativo que surgiu em 1935, no interior da França, com a criação das primeiras Maisons Familiales Rurales ${ }^{4}$ (Casas Familiares Rurais). A PA congrega diferentes valores e experiências formativas, conferindo valorização aos saberes, à cultura e à realidade socioprofissional do jovem camponês no processo de formação (GIMONET, 1998; 2007; SILVA, 2011; 2018). Para tanto, muitas atividades escolares são articuladas a temáticas, às práticas cotidianas e à vida no meio rural, agregando os conhecimentos acumulados pelos joven $s^{5}$ nas suas experiências concretas.

Embora ainda seja um sistema educativo pouco conhecido no meio acadêmico, a PA, por integrar a Educação do $\mathrm{Campo}^{6}$, possui uma proposta teóricometodológica própria que congrega escola, família e comunidade nos processos de formação humana. Tal peculiaridade, por si só, exige que tenhamos uma concepção

4. No território brasileiro, essas unidades educativas são mais conhecidas como Escolas Famílias Agrícolas (EFA) e Casas Familiares Rurais (CFR).

5. Nos CEFFA, alguns termos adotados diferem dos conhecidos nas escolas que oferecem o ensino regular, como por exemplo: 'monitor' = professor; 'jovem' = aluno/estudante/alternante ; CEFFA = escola, etc. (GIMONET, 2007).

6. Considerando a realidade social, cultural e econômica em que vivem os camponeses, a partir da década de 1990, os movimentos sociais que representam os povos do campo (brasileiros) passaram a defender uma escola que seja no e do campo. Assim, compreende-se: No - porque as pessoas têm direito a ser educadas no lugar onde elas vivem, convivem com seus familiares; Do - explica-se pelo fato de que os camponeses têm direito a uma educação pensada sob a ótica das demandas da comunidade local e com a sua participação, vinculada à sua cultura, saberes e às suas necessidades humanas e sociais (CALDART, 2002). 
de campo como espaço de vida, saberes, cultura e identidade próprias, o que requer ajustes e integração da escola à vida social do contexto camponês. Na perspectiva da Educação do Campo, o espaço social denominado campo deixa de ser compreendido como uma extensão dos limites urbanos, notadamente presente nos fundamentos da escola rural ${ }^{7}$.

A proposta de formação criada pela PA apresenta dois espaços e tempos formativos diferentes, representados pelo: Tempo Escola (período de aulas no Centro Familiar de Formação por Alternância $\left(\mathrm{CEFFA}^{8}\right)$ articulado entre estudo, pesquisa e propostas de intervenção) e o Tempo Comunidade (período de vivência na propriedade/ comunidade, pesquisa de estudo, realização de experimentos, trabalho coletivo, etc.) (cf. SILVA, 2011; 2018), além de estar integrados com os Instrumentos Pedagógicos $\left(\mathrm{IP}^{9}\right)$. Evidentemente, a PA possibilita ao jovem oriundo do meio rural aprender não só conhecimentos teóricos sistematizados na academia, mas também saberes ligados à realidade cotidiana do mundo camponês (GIMONET, 2007).

A realização desta pesquisa justifica-se por entendermos que o contexto da PA favorece o desenvolvimento de práticas e eventos de letramento situados. Para investigar como tais práticas e eventos são mobilizados/desenvolvidos nos CEFFA, sobretudo durante o estudo dos temas dos PE para elaboração de textos do gênero CR, realizamos um estudo de natureza etnográfica (ANGROSINO, 2009; ANDRÉ, 2012; GARCEZ et al., 2014) na escola-campo focalizada. Considerando a natureza do objeto investigado, adotaremos neste estudo a abordagem qualitativa e análise interpretativa dos dados gerados (ERICKSON, 1986; MASON, 2002; DENZIN, LINCOLN, 2006).

Na escola-campo, são adotados diferentes IP10, como: (1) Plano de Estudo, (2) Colocação em Comum, (3) Caderno da Realidade, (4) Visita de Estudo, (5) Visita à Família, (6) Projeto Profissional do Jovem, (7) Intervenção Externa, (8) Atividade de Retorno, (9) Acompanbamento Individual, (10) Avaliação Semanal e (11) Cursos (COLINAS, 2015). Tais instrumentos estão inseridos nas atividades escolares em articulação com

7. Durante décadas, inclusive na atualidade, a educação ofertada aos camponeses geralmente acontece(u) nas escolas rurais. Esse tipo de escola é marcado, sobretudo, pelas más condições de funcionamento, professores sem formação inicial mínima exigida pela legislação, currículo e calendário não condizentes com a realidade dos povos do campo.

8. No Brasil, as Casas Familiares Rurais (CFR), as Escolas Familias Agrícolas (EFA) e outras unidades de ensino que adotam a alternância como modo de formação são denominadas de Centros Familiares de Formação por Alternância (CEFFA).

9. Os Instrumentos Pedagógicos são dispositivos de ação que possibilitam ao jovem interagir com a família, com os parceiros da formação, com o conhecimento científico e com o meio socioprofissional e cultural de maneira ativa, buscando formação integral e atuação para o desenvolvimento do meio em que vive (SILVA, 2011).

10. A respeito de concepções e caracterizações do conjunto de IP, consultar Silva $(2011 ; 2018)$. 
os princípios pedagógicos norteadores da formação dos estudantes nos CEFFA. A utilização deles requer não só a colaboração ou participação de outros atores sociais (pais, membros da comunidade, colaboradores da escola, entre outros), mas também dos monitores e dos próprios alternantes envolvidos no processo educativo (SILVA, 2011).

A proposta de formação baseada nos princípios da PA e conduzida nos CEFFA em tempos (Tempo Escola - TE e Tempo Comunidade - TC) diferentes sinaliza - assim como em outras experiências de ensino - a necessidade de os estudantes serem participativos, interessados e observadores, a fim de que possam ter autonomia na formação e construção do conhecimento. Nesse sentido,

[...] o jovem deve aprender pela pesquisa, pela socialização e sistematização dos dados pesquisados, todo conhecimento deve ser reconstruído a luz da realidade que está sendo trabalhada, a experiência deve ser refletida, sistematizada para se tornar conhecimento e ser aplicada em outras realidades (COLINAS, 2015, p. 14).

Com base nesse excerto, percebemos que o desenvolvimento de pesquisas e a socialização de resultados são atividades recorrentes na proposta educativa da PA. Por outro lado, não são pesquisas sobre qualquer tópico ou a serem realizadas em qualquer contexto; na verdade, os alternantes desenvolvem pesquisas acerca de temas que focalizam a própria realidade local. Entende-se que a reflexão deve partir do conhecimento situado nas práticas locais para aquelas mais amplas. É observando e analisando a realidade local que se percebem as demandas; assim, é do conhecimento ou saberes acerca da realidade mais ampla que vêm as contribuições para promoção de intervenções na realidade em que estamos situados.

Na pesquisa em que Silva (2011, p. 26) analisa aspectos constitutivos do Caderno da Realidade (CR) e de textos que compõem esse gênero, levando em consideração o estudo dos temas de diferentes Planos de Estudo (PE), em duas turmas do Ensino Fundamental II, em um CEFFA tocantinense, o autor lembra que "a inovação do ensino com o advento da PA, voltada para atender os jovens oriundos do meio rural, é marcada pela abertura ou ampliação do currículo - até então vigente nos ditames da cultura escolar tradicional". Além de trazer as disciplinas escolares do núcleo comum do currículo, as práticas pedagógicas fomentadas pela PA nos CEFFA também acontecem no decorrer do estudo de temas (PE) ligados à vida associativa, comunitária, profissional e ao meio ambiente, cujo objetivo é proporcionar ao jovem uma formação integral articulada entre atividades dos meios profissional, social, político e econômico, concretizando a práxis. Veremos na sequência que, segundo a proposta de formação da alternância, o Plano de Formação é responsável pela articulação de conteúdos nas dimensões teórica e prática. 


\subsection{O Plano de Formação da Pedagogia da Alternância}

O Plano de Formação (PF), instituído ao longo das experiências da PA, possibilita organizar as disciplinas e os Planos de Estudo (PE) como estratégia para regular a proposta didático-pedagógica orientada pela PA, tornando também mais controlável o processo de produção do gênero Caderno da Realidade. O objetivo desse plano é "[...] formalizar, organizar, visualizar os conteúdos e as finalidades de uma formação eficaz" (SILVA, 2011, p. 36). Ainda segundo o autor, o PF é um plano semelhante a um "plano de ação", uma vez que apresenta as finalidades que orientam a missão educativa de um CEFFA, como a autonomia das pessoas, o desenvolvimento do meio (ou comunidade local) e as metas a serem alcançadas pelos jovens. Portanto, é um plano que apresenta os "conteúdos" do currículo que serão desenvolvidos por alternantes e monitores durante um ano letivo.

Dependendo do nível de ensino (Fundamental ou Médio), o tipo de curso e o propósito de formação do CEFFA, o Plano de Formação pode ser bastante diferente, principalmente em relação aos temas dos PE. Gimonet (2007, p. 70) afirma que "a formação alternada supõe 'dois programas' de formação: o da vida e o da escola. [...]". O plano engloba as disciplinas do núcleo comum do currículo, tais como Português, História, Geografia, Matemática, Biologia, etc. Estas seriam representantes do "programa da formação escolar" (GIMONET, 2007). O PF ainda traz aquelas disciplinas que focalizam "conhecimento da realidade", ou seja, as disciplinas profissionais: Agricultura, Zootecnia, Agroecologia, Economia Rural, etc., cujo papel é favorecer a preparação dos alternantes para a vida socioprofissional. Por tudo isso, a escolha dos temas dos PE para compor um Plano de Formação leva em consideração à realidade local dos estudantes, sendo definidos anualmente com a participação dos estudantes e suas famílias. Portanto, como ilustra a Figura 1, a estruturação do currículo dos CEFFA está articulada diretamente ao PE: 


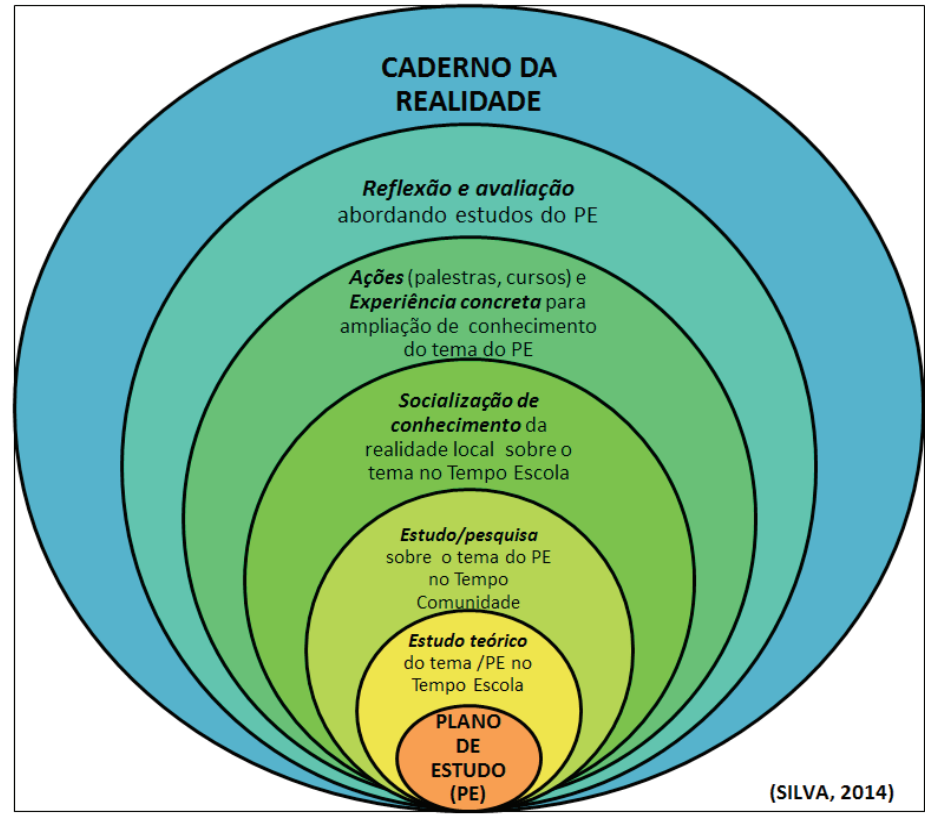

Figura 1. Etapas de execução do Plano de Estudo

Fonte: Silva $(2014$, p. 3).

A Figura 1 mostra que os estudos a respeito do(s) tema(s) do(s) PE ocorrem simultaneamente à produção dos textos que serão incorporados ao Caderno da Realidade (CR). Observamos que a execução de um PE parte da pesquisa sobre os conhecimentos da realidade cotidiana dos jovens em processo de formação para alcançar os conhecimentos da realidade mais ampla, ou seja, do local para o global (SILVA, 2018). Entendemos que por trilhar nessas duas realidades sociais na construção do conhecimento, o jovem é envolvido em práticas de letramento situadas (BARTON, HAMILTON, 2012). Em tais práticas, é necessário articular experiências, conhecimentos e saberes tão heterogêneos e singulares, o que caracterizaria uma "hibridização", ou seja, "[...] processos socioculturais nos quais estruturas ou práticas discretas, que existiam de forma separada, se combinam para gerar novas estruturas, objetos e práticas" (CANCLINI, 2013, p. XIX). Isso porque

As atividades pedagógicas, as disciplinas curriculares, instrumentos pedagógicos e projetos são trabalhados de forma interdisciplinar, iniciando com o tema gerador [PE] e concluindo na atividade de retorno. Todo esse processo está organizado no plano de formação da escola, construindo e reconstruindo continuamente com a colaboração de estudantes, familiares, servidores da escola e outros parceiros (COLINAS, 2015, p. 14) 
Logo, os temas geradores dos PE, previstos no Plano de Formação dos CEFFA para cada ano letivo, tornam-se os conteúdos de registros dos CR. Por isso, o CR "[...] é o instrumento de sistematização da reflexão e da ação provocada pelo plano de estudo" (SILVA, 2011, p. 89, grifo nosso). Ou seja, a construção desse gênero pode favorecer a uma "preparação" do indivíduo de maneira integral, inserido em uma relação dialógica com diferentes atores sociais na construção de conhecimento na esfera escolar, familiar e comunidade local. Evidentemente, as práticas educativas recorrentes na $\mathrm{PA}$, além de serem mediadas por diferentes Instrumentos Pedagógicos, são peculiares à realidade da vida no meio rural e à realidade da comunidade camponesa que circunscreve um CEFFA. Como veremos, a abordagem etnográfica se constitui como uma opção metodológica que oferece subsídios importantes ao desenvolvimento de pesquisas que focalizam práticas de letramento no âmbito dos estudos da linguagem nesse contexto educativo.

\section{CONTRIBUIÇÕES DA ETNOGRAFIA À PESQUISA NO CONTEXTO DA PEDAGOGIA DA ALTERNÂNCIA}

O método etnográfico de pesquisa foi desenvolvido nas investigações da área da Antropologia, voltadas ao estudo da cultura e da sociedade por meio da descrição, documentação e análise de aspectos cotidianos de povos diferentes. Diferentemente da Antropologia, em que o investigador permanece longo tempo no campo (ou comunidade), mergulha na cultura de outras comunidades e adota diferentes categorias sociais a serem aplicadas na análise dos dados, dependendo do objeto investigado, a exemplo de estudos focalizando ensino de línguas, as pesquisas etnográficas não exigem que os pesquisadores cumpram literalmente os mesmos parâmetros investigativos adotados em pesquisas antropológicas. Isso porque os etnógrafos dessa área concentram seus esforços na descrição da cultura de determinado grupo social, como hábitos, rituais, crenças, valores, linguagens, significados (cf. ANGROSINO, 2009). Por outro lado, no âmbito do ensino, os investigadores realizam estudos focalizando a escola, os atores sociais, as diferentes práticas de ensino, as formas de organização pedagógica, interação professor/aluno, entre outros aspectos (ANDRÉ, 2012).

No contexto escolar, por apresentar algumas peculiaridades, sobretudo em relação aos tipos de atividades e interações dos atores sociais nas práticas educativas que podem ser registradas, a etnografia ganha outros contornos, embora tenha de manter certa proximidade com a etnografia desenvolvida no âmbito da Antropologia. Ao efetuarmos pesquisa etnográfica a respeito dos letramentos no contexto escolar, 
por exemplo, certamente a perspectiva teórico-metodológica assumida deve focalizar a escrita ensinada/aprendida, o que as pessoas sabem, como/quando usam a escrita. Esses aspectos vão além de "mensurar o domínio" de simples habilidades de uso da linguagem. No presente estudo, tais aspectos serão contemplados.

Os antropólogos valorizavam em suas pesquisas apenas os textos das tradições orais do "outro", como canções, poemas e encantamentos (cf. BARTON, PAPEN, 2010). Os gêneros orais possibilitavam conhecer crenças e costumes das comunidades ou grupos sociais estudados. Com isso, a escrita e o letramento ocupavam posição marginal nas pesquisas antropológicas. Entretanto,

Examinar textos escritos é essencial para compreender como as sociedades funcionam e são organizadas, como as instituições comunicam com o público, como o trabalho está sendo feito, como indivíduos e grupos sociais organizam suas vidas e dão sentido a suas experiências e como as culturas em todas as suas variações são produzidas e reproduzidas (BARTON, PAPEN, 2010, p. 5, tradução nossa) ${ }^{11}$.

A escrita, por sua natureza, está ligada diretamente aos aspectos social e cultural dos grupos sociais ou comunidades. Não podemos esquecer que valores, costumes, crenças e comportamentos vinculam-se, direta ou indiretamente, aos textos que escrevemos ou lemos. E a etnografia apresenta características apropriadas ao estudo da escrita na perspectiva antropológica, bem como de abordagem qualitativa.

Desse modo, nas pesquisas de natureza etnográfica desenvolvidas no contexto educacional, o investigador deve concentrar seu olhar nas diferentes situações de interação nas mais variadas práticas empreendidas pelos participantes ou colaboradores, embora seja necessário ter um cuidado substancial com o processo, isto é, com o curso em que as atividades seguem, e não com o produto ou resultados finais (ANDRÉ, 2012).

Segundo Mason, o método de observação participante adotado nas pesquisas de natureza etnográfica permite ao investigador observar e registrar diferentes tipos de elementos do contexto em que estão inseridos os atores sociais, como "[...] ações sociais, comportamentos, interações, relacionamentos, eventos, assim como as dimensões espacial, temporal e de localização" (MASON, 2002, p. 84, tradução nossa $)^{12}$. A autora ainda destaca que, para gerar dados usando o método etnográfico, o pesquisador deve fazer uma "imersão" no contexto social da pesquisa

11. Do original em Inglês: "Examining written texts is essential for understanding how societies operate and are organized, how institutions communicate with the public, how work is being done, how individuals and social groups organize their lives and make sense of their experiences and how cultures in all their variations are produced and reproduced".

12. Do original em Inglês: "[...] social actions, behaviour, interactions, relationships, events, as well as spatial, locational and temporal dimensions". 
para que possa observar e registrar experiências específicas. Por isso, a pesquisa observacional requer período prolongado e recurso para ser excutada.

Durante o desenvolvimento do nosso estudo, como pesquisador, presenciamos, vivenciamos e registramos experiências e atividades educativas singulares. Nas palavras de Mason (2002), a observação participante gera conhecimento ou evidência do mundo social, além de permitir que sejam gerados dados que não podem ser obtidos de outra maneira.

Particularmente, a etnografia ofereceu subsídios importantes durante todo o desenvolvimento da pesquisa (na escola e nas comunidades envolvidas) a respeito do nosso objeto de estudo. Mason lembra que "o trabalho de campo inclui a observância e análise do ambiente da pesquisa como uma forma de realização da cultura. Ao mesmo tempo, o nosso acoplamento com o campo é tanto intelectual e físico" (MASON, 2002, p. 87, tradução nossa) ${ }^{13}$. Para realizar o trabalho de campo no CEFFA, além de ter de conhecer a proposta formativa da PA e seus Instrumentos Pedagógicos (IP), durante um ano de atividades da pesquisa foi estabelecido um vínculo com a escola. $\mathrm{O}$ contato com a equipe de monitores colaboradores e com a direção da escola foi constante, pois necessitávamos acompanhar e registrar todas as atividades que envolviam o desenvolvimento dos temas dos Planos de Estudo (PE) da turma participante da pesquisa.

Nosso trabalho de campo realizado na Escola Família Agrícola e nas comunidades dos alunos colaboradores, além de nos permitir focalizar e registrar diferentes práticas de letramento mediadas pelos IP da PA e principalmente pelos estudos dos $\mathrm{PE}$, proporcionou-nos condições para que pudéssemos conhecer de forma bastante detalhada o funcionamento da instituição de ensino, como organização pedagógica, interação entre monitores/estudantes durante estudos dos temas dos PE e os atores sociais colaboradores (monitores, estudantes e pessoas da comunidade) da pesquisa ${ }^{14}$.

13. Do original em Inglês: "Fieldwork includes the observance and analysis of the body as an embodiment of culture. At the same time our engagement with the field is both intellectual and physical".

14. Nossa pesquisa, por focalizar atividades de diferentes aspectos empreendidas por atores sociais em interações escolares, exigiu uma inspeção minuciosa para "construção" de dados de pesquisa representativos do contexto de investigação. Por isso, adotamos o uso do termo "geração" em vez de "coleta" de dados (GARCEZ et al., 2014). Para Mason (2002), o termo gerar dados expressa com mais precisão o trabalho de campo desenvolvido pelo pesquisador, pois este constrói conhecimento orientado por métodos oriundos do trabalho de investigação, sendo dotado de natureza intelectual, analítica e interpretativa. Porém, também houve coleta de dados em nosso estudo, aqui representados por documentos cedidos pela escola-campo. 
Portanto, em função da existência dos vários IP que integram as práticas didático-pedagógicas orientadas pelos princípios da alternância, principalmente por exigir que os alternantes realizem visitas de estudo e pesquisas nas comunidades ao longo de um ano letivo acerca dos temas dos (08) PE e entrevistem atores sociais locais, em nossa pesquisa tivemos que acompanhá-los durante o Tempo Comunidade em diferentes momentos e registrar tais atividades. Daí, a etnografia pode ser tomada como um método apropriado (no âmbito dos estudos da linguagem) por favorecer o desenvolvimento de pesquisas no contexto de ensino da Pedagogia da Alternância, como veremos na sequência.

\subsection{A etnografia e a geração de dados nas práticas educativas da Pedagogia da Alternância}

De acordo com as atividades/ações registradas durante a pesquisa, a etnografia é um método mais completo, apropriado e oferece as ferramentas necessárias para que o pesquisador possa gerar ou coletar dados no contexto educativo da alternância, em especial por nosso estudo envolver questões de uso da linguagem. Por outro lado, o processo de formação originário do contexto de ensino da PA envolve (direta ou indiretamente) uma rede de parceiros coformadores (cf. GIMONET, 1998). Conforme enunciado anteriormente, tal rede é composta por monitores e profissionais/técnicos voluntários de entidades parceiras do CEFFA, cuja natureza das atividades/ações desempenhadas por tais atores nos permite depreender que eles ocupam o papel de agentes de letramento, sobretudo na execução dos Instrumentos Pedagógicos (IP).

Segundo Kleiman (2014, p. 88), "o agente de letramento, que pode ser o professor, um voluntário da comunidade, um pesquisador, orienta o trabalho do aluno fornecendo materiais relevantes e modelos de atividades significativas". Nas práticas educativas propostas pela alternância, os monitores (e profissionais voluntários) articulam atividades/ações coletivas e delas participam com o grupo de alternantes, interagem com outros monitores, coordenadores, pais, pessoas da comunidade, no intuito de fortalecer os IP e ampliar o leque de atividades vinculadas à formação dos jovens aprendizes envolvidos.

Para efeitos deste estudo, concentramos as discussões somente em alguns IP, os quais estão integrados aos estudos dos temas dos Planos de Estudo (PE), e constituem seções específicas do Caderno da Realidade (CR), como (1) Pesquisa do PE, (2) Colocação em Comum, (3) Intervenção Externa e (4) Visita de Estudo. Na escola-campo, as atividades pedagógicas relacionadas ao conjunto de IP elencado anteriormente são organizadas em quatro grupos: i) Ação no Internato; ii) Ação na Comunidade; iii) Ação no/ 
na Internato/Comunidade; e iv) Ações Organizacionais (cf. COLINAS, 2015; SILVA, 2018). Daí, a utilização desses IP nas práticas educativas em alternância requer a execução de atividades/ações envolvendo os estudos dos temas dos PE nos Tempo Escola (internato) e Tempo Comunidade, seja por meio de ações na comunidade (Pesquisa do PE, Visita de estudo) ou ações no próprio recinto do CEFFA.

Por focalizar práticas e eventos de letramento no contexto da PA, a pesquisa contempla ações didáticas empreendidas pelos monitores na construção de um objeto de ensino singular - o gênero discursivo CR (SILVA et al., 2015). Nesse sentido, tomamos o CR como ferramenta do processo de transposição didática ${ }^{15}$ interna (CHEVALLARD, 1991[1985]) em um contexto educativo orientado pelos princípios teórico-metodológicos da PA. Por isso, faz-se necessário compreender, principalmente, dois aspectos fundamentais, como: (i) objetos de ensino e os (ii) Instrumentos Pedagógicos da PA. Com base na pesquisa de campo, identificamos a ação de atores sociais e os produtos originários das relações estabelecidas entre os diferentes níveis, conforme ilustrado no Quadro 1:

Quadro 1. Níveis de transposição didática, atores e produtos

\begin{tabular}{|c|l|l|}
\hline NÍVEIS & \multicolumn{1}{|c|}{ ATORES SOCIAIS } & \multicolumn{1}{c|}{ PRODUTOS } \\
\hline SABER A ENSINAR & $\begin{array}{l}\text { Trabalho dos idealizadores } \\
\text { da PA (Membros dos } \\
\text { CEFFA e do Conselho Nac. } \\
\text { de Educação, Monitores } \\
\text { especialistas, Pesquisadores } \\
\text { da PA, etc.). }\end{array}$ & $\begin{array}{l}\text { Princípios (ou pilares) da PA, Resoluções } \\
\text { do Conselho Nac. de Educação, Projeto } \\
\text { Político-Pedagógico, Plano de curso, } \\
\text { Propostas e Grades curriculares, etc. }\end{array}$ \\
SABER & $\begin{array}{l}\text { Trabalho dos autores, } \\
\text { Diretores, Coordenadores, } \\
\text { Monitores e membros dos } \\
\text { CEFFA. }\end{array}$ & $\begin{array}{l}\text { Livros, revistas, cadernos, apostilas, } \\
\text { material audiovisual, Plano de Formação, } \\
\text { Planos de Estudo, etc. }\end{array}$ \\
\hline SABER ENSINADO & $\begin{array}{l}\text { Trabalho do monitor e atores } \\
\text { sociais da comunidade. }\end{array}$ & $\begin{array}{l}\text { Notas na lousa, exibição de } \\
\text { documentários e imagens, exposição } \\
\text { oral, entrevistas, Visitas de estudo, } \\
\text { Questionário de pesquisa, Colocação } \\
\text { em comum, etc. }\end{array}$ \\
\hline SABER & Trabalho do estudante. & $\begin{array}{l}\text { Gênero CR, saberes diversos sobre } \\
\text { os temas dos PE e a Comunidade que } \\
\text { circunscreve o CEFFA. }\end{array}$ \\
\hline APRENDIDO & \multicolumn{2}{|c|}{}
\end{tabular}

Fonte: Adaptado de Oliveira (2013, p. 87).

15. Por não ser o foco principal da pesquisa, não aprofundaremos a discussão sobre transposição didática interna e externa. Para maiores detalhes, ver Chevallard (1991[1985]).

16. O saber didatizado, de acordo com Oliveira (2013, p. 86), " [...] corresponde ao resultado da interação entre o saber a ensinar, o saber ensinado e as práticas sociais de referência". 
Os dados desse quadro reforçam, sobretudo nos níveis Saber ensinado e Saber aprendido, que devemos valorizar o contexto social e os saberes dos atores sociais que circunscrevem ou que estão inseridos na escola-campo. E o desenvolvimento de atividades como: tomada de notas na lousa, exibição de documentários e imagens, exposição oral, entrevistas; Visitas de estudo; Questionário de pesquisa e Colocação em comum durante estudo dos temas dos PE acontece por meio de práticas educativas que potencializam o(s) letramento(s) dos jovens. Aliás, os dados da pesquisa também nos permitem identificar quais gêneros discursivos (principalmente o $C R$ ) vão se constituir como objetos de ensino nas EFA, assim como as respectivas práticas de letramento em que eles emergem.

Conforme explicitado anteriormente, as práticas educativas orientadas pela PA exigem o estabelecimento de um Plano de Formação (PF), cuja execução das atividades pedagógicas (incluindo-se a produção do $\mathrm{CR}$ ) ocorre em dois momentos formativos: (1) Tempo Escola (aulas no CEFFA) e (2) Tempo Comunidade (vivência, estudo, pesquisa na propriedade) (SILVA, 2011). A exemplo de nossa pesquisa, durante o ano letivo de 2014 os monitores trabalharam com os jovens da turma colaboradora 08 (oito) Planos de Estudo (PE) ou temas geradores elencados no Plano de Formação da escola-campo e que resultaram nos textos integrantes do $\mathrm{CR}$, cujo desenvolvimento das diferentes atividades ocorreu de maneira alternada entre Tempo Escola (TE) e Tempo Comunidade (TC). Além disso, os PE eram constituídos de temáticas diferentes e vinculadas à realidade dos estudantes em processo de formação, conforme apresentado no Quadro 2:

Quadro 2. Temas dos Planos de Estudo (PE)

\begin{tabular}{|c|c|c|c|c|}
\hline PE & Tema gerador do PE & $\begin{array}{c}\text { Período de } \\
\text { Execução }\end{array}$ & $\begin{array}{c}\text { Monitor } \\
\text { responsável }^{17}\end{array}$ & $\begin{array}{c}\text { Formação do } \\
\text { Monitor }\end{array}$ \\
\hline 01 & Agricultura familiar & $24 / 02$ a $14 / 03 / 2014$ & Décio & Téc. Agropecuário \\
\hline 02 & Solo & $14 / 03$ a $11 / 04 / 2014$ & Nilson & Geógrafo \\
\hline 03 & Criação de aves & $11 / 04$ a $16 / 05 / 2014$ & Jonas & Zootecnista \\
\hline 04 & $\begin{array}{c}\text { Jardinagem e } \\
\text { paisagismo }\end{array}$ & $16 / 05$ a $13 / 06 / 2014$ & Pablo & $\begin{array}{c}\text { Matemático / Téc. } \\
\text { Agropecuário }\end{array}$ \\
\hline 05 & Olericultura & $08 / 08$ a 05/09/2014 & Virgulino & Matemático \\
\hline 06 & Piscicultura & $05 / 09$ a 03/10/2014 & Jonas & Zootecnista \\
\hline 07 & Apicultura & $03 / 10$ a $31 / 10 / 2014$ & Jonas & Zootecnista \\
\hline 08 & Agroextrativismo & $31 / 10$ a $28 / 11 / 2014$ & Nilson & Geógrafo \\
\hline
\end{tabular}

Fonte: Pesquisa do autor (2014).

17. Por questões éticas, os nomes de todos os colaboradores desta pesquisa foram substituídos por pseudônimos. 
Esse quadro traz detalhes importantes relacionados a cada um dos temas geradores, como a ordem de estudo ou a aplicação do PE, o monitor responsável pela aplicação do $\mathrm{PE}$, além da área de formação dos monitores. Na coluna período de execução, são apresentadas as datas de início e encerramento dos estudos de cada um dos PE. Conforme proposto, na escola-campo são estudados ou desenvolvidos em média 02 (dois) PE por bimestre. Vale ressaltar que os textos produzidos pelos alunos colaboradores durante as atividades e pesquisas desenvolvidas a respeito do conjunto de temas (conteúdos) dos PE apresentados no Quadro 2 compõem os registros dos 16 (dezesseis) CR do corpus. Portanto, o CR é um gênero construído ao longo de um ano letivo concomitante com o estudo de 08 (oito) temas geradores diferentes vinculados às atividades do campo e da realidade do jovem camponês. Tal particularidade na construção do CR nos permite tomá-lo como um gênero catalisador (SIGNORINI, 2006). Ele é um gênero que emerge de práticas sociais situadas em contextos de uso da linguagem (escola, família, comunidade), das quais os jovens participam nas interações (orais e escritas) para produção de seus textos durante o TE e o TC. Considerando as especificidades das atividades que desencadeiam sua produção no contexto de ensino da PA,

[...] o Caderno da Realidade é um gênero que possibilita sistematizar e organizar os conhecimentos escolares em seus textos segundo a realidade das práticas educativas empreendidas nos CEFFA. Para ele existir, são necessárias diferentes atividades de linguagem empreendidas em diferentes esferas, como na escolar, na familiar e na comunidade (SILVA, 2011, p. 70).

Silva (2011), com base em um estudo de Bronckart (2009), explica que em seu plano geral o CR incorpora e reelabora em sua estrutura composicional diferentes gêneros ${ }^{18}$, como Pesquisa do PE, Colocação em comum, Sintese do PE: minha realidade, Intervenção Externa, Visita de estudo e Conclusão e avaliação do PE. Essas seções vão apresentar os registros a respeito de cada um dos temas dos PE ilustrados no Quadro 2. É importante ressaltar que quando nos referimos à infraestrutura de um gênero, estamos tratando da organização dos conteúdos, dos tipos de discursos e dos tipos de sequências textuais mobilizadas pelo agente-produtor ou estrutura composicional ${ }^{19}$. Nas palavras de Bronckart (2009, p. 120, grifo do autor), "o plano geral refere-se à organização de conjunto do conteúdo temático; mostra-se visível no processo de leitura e pode ser codificado em um resumo". Logo, a finalidade do

18. Para maiores detalhes a respeito desses gêneros, consultar Silva $(2011$; 2018) e Silva et al. (2015).

19. As sequências textuais são mais conhecidas como narrativa, argumentativa, descritiva, explicativa (ou expositiva), dialogal e injuntiva. 
plano geral é apresentar na forma de um resumo como o seu conteúdo se organiza na discursividade do texto.

Conforme a proposta formativa da alternância e utilização dos IP, os desdobramentos das atividades ou ações envolvendo estudos dos temas dos PE (ver Quadro 2) e geração dos textos que compõem o CR, de fato, envolveram escola, família e comunidade, como ilustra o Quadro 3:

\section{Quadro 3. Estudo dos PE e Construção do Caderno da Realidade}

\begin{tabular}{|c|c|}
\hline $\begin{array}{c}\text { Esfera escolar - Tempo Escola } \\
\text { (Práticas escolares internas) }\end{array}$ & $\begin{array}{l}\text { Esfera familiar/comunidade - Tempo } \\
\text { Comunidade } \\
\text { (Práticas escolares externas) }\end{array}$ \\
\hline $\begin{array}{l}\text { 1. Exposição oral sobre o Caderno da Realidade } \\
\text { e a alternância; } \\
\text { 2. Exposição oral sobre os temas dos PE; } \\
\text { 3. Usos de slides para exposição sobre os temas } \\
\text { dos PE; } \\
\text { 4. Exibição de vídeos a respeito dos temas dos } \\
\text { PE; } \\
\text { 5. Elaboração coletiva do questionário Pesquisa } \\
\text { do PE; } \\
\text { 6. Colocação em comum - Apresentação dos } \\
\text { resultados da pesquisa sobre os PE; } \\
\text { 7. Síntese das respostas às questões dos PE com } \\
\text { escrita na lousa; } \\
\text { 8. Orientações dos monitores e (re)escrita dos } \\
\text { textos do CR pelos alunos. }\end{array}$ & $\begin{array}{l}\text { 1. Entrevista oral com um camponês; } \\
\text { 2. Leitura do script/questionário Pesquisa do PE; } \\
\text { 3. Tomada de notas durante entrevista; } \\
\text { 4. Escuta e transcrição de gravações das } \\
\text { entrevistas; } \\
\text { 5. Elaboração de textos do CR; } \\
\text { 6. Visita de estudo sobre tema dos PE (in loco). }\end{array}$ \\
\hline
\end{tabular}

Fonte: Pesquisa do autor (2014).

Apesar de serem implementadas diferentes atividades ligadas ao letramento ao longo do processo de estudo dos temas dos PE e da produção do gênero CR nos Tempo Escola (TE) e Tempo Comunidade (TC), entendemos que todas elas (internas/externas) são originárias e vinculam-se direta ou indiretamente ao domínio escola. No entanto, independentemente do elo estreito que as práticas e eventos de letramento desenvolvidos na esfera familiar/comunidade no TC tenham com a cultura escolar, apresentam peculiaridades ou singularidades e permitem que os estudantes apropriem-se de saberes da cultura local que não são legitimados nas práticas de escolarização mais conservadoras. Conforme ilustrado no Quadro 3 , as atividades focalizadas em nossa pesquisa são bastantes e de natureza diversa, 
corroborando uma das características da etnografia. Por outro lado, a gama de dados gerados reflete também os diferentes contornos do objeto em estudo vislumbrados pelo investigador na pesquisa qualitativa. Como pesquisadores, precisamos estar cientes de que, nas pesquisas de observação participante, a geração de dados seria como "escavar ou construir conhecimentos e dados" (MASON, 2002, p. 88), tendo cuidado com os limites de nossa participação no campo da pesquisa. No próximo tópico, analisaremos parte dos dados gerados no decorrer da pesquisa.

\section{ANÁLISE DE DADOS}

Para demonstrar como a etnografia pode contribuir significativamente para o desenvolvimento de pesquisas no contexto de ensino da PA, especialmente quando contempla os Planos de Estudo (PE) e usos da linguagem (oral ou escrita), analisamos alguns dados gerados durante os estudos realizados pelos colaboradores da pesquisa (no Tempo Escola e Tempo Comunidade) a respeito do PE 01-Agricultura familiar apresentado no Quadro 2. Focalizaremos, então, as etapas de atividades da (1) Pesquisa do PE, (2) Colocação em Comum, (3) Intervenção Externa, (4) Visita de Estudo e respectivos registros da colaboradora Nelma ${ }^{20}$ e do colaborador Leomar ${ }^{21}$ nas seções específicas do Caderno da Realidade (CR).

As diferentes atividades ou etapas de execução dos estudos do PE focalizado foram coordenadas pelo monitor Décio ${ }^{22}$, Técnico em Agropecuária.

\subsection{Pesquisa do PE}

Os estudos envolvendo o tema de um PE na alternância, em geral, iniciam-se ao final de uma semana de aulas do Tempo Escola (TE). Segundo apresentado no Quadro 2, para cada tema há um monitor responsável pela coordenação das diferentes etapas de atividades. Com o objetivo de preparar os estudantes antes de saírem do CEFFA para o Tempo Comunidade (TC) ou meio familiar/socioprofissional, o monitor responsável por determinado PE executa o que denominam "aplicação do PE". A duração dessa atividade pode levar de 1 (uma) a 2 (duas) horas e o agente de

20. O monitor Pablo, que é Técnico em Agropecuária e Licenciado em Matemática, foi o orientador da colaboradora Nelma na produção do CR.

21. Durante os estudos dos temas dos (08) PE e produção do CR em 2014, Leomar contou com as orientações da monitora Oneide, que é Licenciada em Pedagogia e atua na escola-campo há um ano.

22. Possui curso de Graduação em Tecnólogo Superior em Logística e Pós-Graduação Lato Sensu em Educação do Campo, Agricultura Familiar e Envolvimento Social no Tocantins, além de acumular bastante experiência na alternância. 
letramento (monitor) responsável pode trabalhar o tema com a turma conforme a didatização escolhida, incluindo-se: (i) uma aula em forma de seminário a respeito do $\mathrm{PE}$ - conceituando-o, caracterizando-o, etc.; (ii) uso de slides para exposição acerca do tema do $\mathrm{PE}_{i}$ (iii) exibição de vídeos focalizando o assunto; (iv) esclarecimento de dúvidas e perguntas dos estudantes vinculadas ao tema em estudo. Ao final, como mediador do processo, o monitor prepara (sistematiza e elabora) com os alternantes um 'conjunto de questões' (Pesquisa do PE) a respeito do tema do PE a ser aplicado na comunidade durante o TC. Além de ser um espaço para introdução do tema alvo do estudo, os estudantes ainda recebem orientações relacionadas aos procedimentos de entrevista na comunidade, quem deve ser o(a) entrevistado(a) e como devem ser registradas as respostas do questionário na respectiva seção (Pesquisa do PE) no gênero Caderno da Realidade (CR).

Em 2014, de acordo com o cronograma do Plano de Formação da escolacampo, o primeiro dos 08 (oito) Planos de Estudo (PE) traz como tema Agricultura familiar (ver Quadro 2). Evidentemente, é uma temática ligada diretamente à realidade dos jovens camponeses e suas famílias, de fundamental importância para o desenvolvimento socioeconômico do campo. Talvez tenha sido esse o motivo da escolha. O excerto a seguir traz parte dos registros do pesquisador acerca das ações do monitor Décio durante a aplicação do referido PE:

\begin{tabular}{|l|}
\hline Exemplo 01. Pesquisa do PE \\
\hline O monitor abordou o tema conceituando-o, caracterizando-o, citando \\
Programas e Órgãos ou entidades que apoiam o agricultor familiar. Explicitou \\
as características que uma propriedade deve ter para ser incluída dentro dos \\
Programas que fomentam a Agricultura familiar. Para ampliar a exposição sobre o \\
tema, foram exibidos dois vídeos do Globo Rural: VPE1-011-A força da agricultura \\
familiar e VPE1-013 - Veja a participação da agricultura familiar na produção de biodiesel, \\
sendo que ambos focalizam a importância e o fortalecimento da Agriculturafamiliar \\
no Brasil. Depois de assistirem a esses vídeos, o docente fez perguntas aos jovens, \\
respondeu questões, o que mostrou interação durante a aula. \\
Com o apoio de datashow e notebook, na sequência iniciou-se a formulação do \\
questionário Pesquisa do PE. Foi usado o notebook para digitar e o datashow para exibir \\
as questões construídas coletivamente. Não havia nenhuma questão pronta. Para \\
formulá-las, ele pediu aos estudantes que elaborassem sugestões de questões a \\
respeito do tema Agricultura familiar, sendo apresentadas na sequência. Por sua \\
vez, o monitor apenas reformulava ou reestruturava o enunciado das questões. \\
(PE Agricultura familiar: Pesquisa do PE. Diário de Campo. N. 001/2014.). \\
\hline
\end{tabular}


O Exemplo 01 apresenta informações importantes relacionadas à primeira etapa de estudo do tema do PE 01 - Agricultura familiar, ocorrida na escola-campo. Esse fragmento do Diário de campo do pesquisador produzido durante a observação participante traz informações detalhadas que englobam a abordagem do tema pelo monitor, materiais didáticos utilizados e a opção didática para construção do questionário Pesquisa do PE. Ao delegar aos alunos da turma a tarefa de elaborar a primeira versão das questões e apresentá-las, o monitor deixa de ser o único "detentor da palavra" em sala de aula. Os jovens têm oportunidade de manifestar suas vozes nos enunciados das questões, embora o monitor possa fazer intervenções com o objetivo de aperfeiçoa-las, sobretudo em relação ao emprego da língua. Além de valorizar a participação dos alunos, tal condição favorece o(s) letramento(s) dos atores envolvidos.

Por outro lado, "a Pesquisa do PE é um gênero de grande importância para a constituição do CR na PA, principalmente pelo fato de instigar o jovem a fazer questionamentos, a desenvolver uma pesquisa sobre o tema de um PE na comunidade em que vive" (SILVA et al., 2015, p. 363). Por constituir uma das seções de registros das atividades de cada um dos temas geradores (ver Quadro 2) no CR, o objetivo da Pesquisa do PE é levar o jovem a registrar, por meio de 'sequências dialogais' (questões/perguntas), o 'depoimento' de um ator da comunidade local que tenha suas atividades vinculadas ao tema do PE em estudo, sendo os entrevistados os pais do aluno ou outros atores da comunidade. Tal condição se define para que algum colaborador possa contribuir com respostas às questões, já que pode tornar mais verossímil a realidade do tema na comunidade do estudante. Na proposta formativa da PA, o jovem precisa ampliar os conhecimentos acerca da família, da comunidade, da própria realidade em que está inserido (SILVA et al., 2015), o que ocorre mediante execução do IP Pesquisa PE.

\subsection{Colocação em Comum}

A Colocação em comum é, por sua natureza, uma atividade de socialização dos resultados de pesquisas sobre os temas do PE. Mas há outras atividades de um CEFFA que utilizam a Colocação em comum. Por isso, ela possibilita conhecer e partilhar as descobertas, os ganhos e as contribuições para a formação de cada um dos alternantes. É um instrumento pedagógico que dá "poder de voz" a cada um e ao grupo (de estudantes e monitores). Esse IP promove uma cooperação efetiva no que diz respeito à valorização de diferentes saberes no processo de formação dos alternantes (GIMONET, 1998).

$\mathrm{Na}$ sequência, apresentamos um excerto do nosso diário de campo produzido durante a realização das atividades da etapa Colocação em comum a respeito do tema do PE Agricultura familiar, coordenada pelo monitor Décio: 
Exemplo 02 - Colocação em comum

Nesta etapa - Colocação em comum, foram convidados três alunos para sintetizar, 'condensar' as respostas apresentadas pela turma e transcrevê-las na lousa. Eram os 'redatores' da aula. O monitor apenas coordenou as atividades, dirigindo cada questão a determinado jovem para que pudesse responder. Quando as respostas eram inapropriadas ou insuficientes, outros alunos eram convidados pelo monitor a responder, ampliando-se a resposta esperada para a questão. (PE Agricultura familiar: Colocação em comum. Diário de Campo. N. 003/2014.).

A didatização adotada pelo monitor - embora esse profissional não tenha formação em curso de licenciatura - nessa etapa de estudo do PE focalizado reforça que as opções didáticas são dignas de reconhecimento não só por incentivar os estudantes a conduzirem a própria Colocação em comum, mas sobretudo por criar condições para que os jovens em formação possam discutir, dialogar o próprio saber na práxis. Além de terem registrado a Colocação em comum na modalidade escrita da língua materna no $\mathrm{CR}$, os estudantes que conduziram a atividade tiveram a oportunidade de usar a oralidade para apresentar ou socializar os resultados de suas pesquisas, o que representa uma prática de letramento importante em sala de aula.

O texto (Figura 2) ilustrado na sequência faz parte do CR produzido pelo colaborador Leomar, aluno da turma do $1^{\mathrm{O}}$ ano do Ensino Médio da escola-campo em 2014:

\begin{tabular}{|c|c|}
\hline 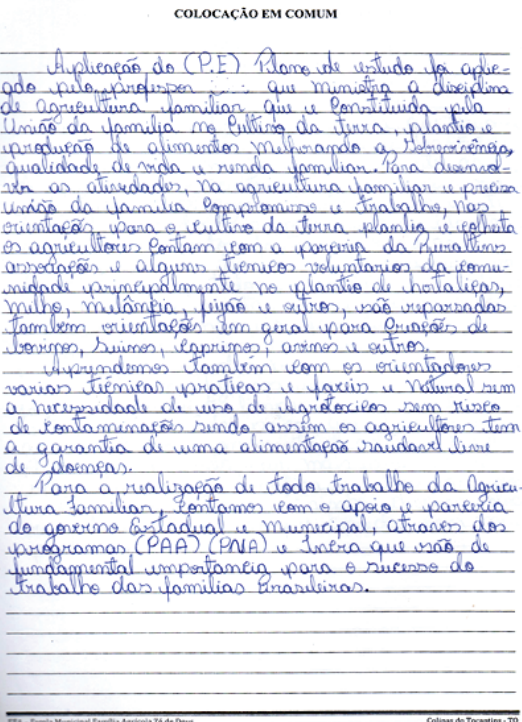 & $\begin{array}{l}\text { COLOCAÇÃO EM COMUM } \\
\text { Agricultura Familiar } \\
\text { Aplicação do (PE) Plano de estudo foi aplicado pelo } \\
\text { professor Décio que ministra a disciplina de Agricultura } \\
\text { familiar que é constituída pela união da família no cultivo da } \\
\text { terra, plantio e produção de alimentos melhorando a } \\
\text { sobrevivência, qualidade de vida e renda familiar. Para } \\
\text { desenvolver as atividades, na agricultura familiar e preciso } \\
\text { união da familia compromisso e trabalho, nas orientações } \\
\text { para o cultivo da terra plantio e colheita os agricultores } \\
\text { contam com parceria da Ruraltins, associações e alguns } \\
\text { técnicos voluntários da comunidade principalmente no } \\
\text { plantio de hortaliças, milho, melância, feijão e outros, são } \\
\text { repassadas também orientações em geral para criações de } \\
\text { bovinos, suínos, caprinos, ovinos e outros. } \\
\text { Aprendemos também com os orientadores varias } \\
\text { técnicas praticas e faceis e natural sem a necessidade de uso } \\
\text { de agrotóxicos sem risco de contaminações sendo assim os } \\
\text { agricultores tem a garantia de uma alimentação saudável livre } \\
\text { de doenças. } \\
\text { Para a realização de todo trabalho da Agricultura } \\
\text { Familiar, contamos com o apoio e parceria do governo } \\
\text { Estadual e municipal, através dos programas (PAA) (PNA) e } \\
\text { Incra que são de fundamentalimportância para o sucesso do } \\
\text { trabalho das famílias brasileiras. } \\
\text { (Colaborador Leomar, CR } 07,1^{\circ} \text { Ano, 2014, p. 3) }\end{array}$ \\
\hline
\end{tabular}

Figura 2. Colocação em comum - PE Agricultura familiar - Registro no CR 
Esse texto da Figura 2 apresenta uma síntese da Colocação em comum a respeito do tema do PE Agricultura familiar. Não podemos deixar de reconhecer que, do ponto de vista do letramento escolar, é uma produção escrita que demanda revisões. Evidentemente, as inadequações dizem respeito ao uso da língua na modalidade escrita e poderiam ser solucionadas com a adoção da reescrita por parte dos monitores (formadores) responsáveis pelas orientações dos estudantes na produção do CR (cf. SILVA, 2011).

Por outro lado, a produção do texto evidencia que o colaborador Leomar foi capaz de produzir um texto bastante informativo e fiel aquilo que estudaram a respeito do PE focalizado, com boa progressão temática, bem estruturado quanto à paragrafação e que materializa os resultados de uma ampla negociação entre diversos atores sociais, colocados como coautores, sujeitos que aprendem uns com os outros na interação dialógica (BAKHTIN, 2006) e não apenas com o monitor. A escola tradicional tem quase sempre apenas um autor (aluno solitário) para um único leitor (professor). Na alternância, esses textos que compõem os CR têm razão de ser, são produzidos colaborativamente e os estudantes vão amadurecendo a capacidade de análise da produção em processo.

Tendo em vista o conhecimento construído pelos alternantes ao terem a oportunidade de estudar o tema do PE Agricultura familiar, a Figura 2 sintetiza pontos importantes e que, para o colaborador Leomar, são considerados os mais significativos, destacando-se: (i) importância da união e trabalho da família no cultivo da terra; (ii) produção de alimentos para melhorar a qualidade de vida e a renda familiar camponesa; (iii) assistência técnica de órgãos como Instituto de Desenvolvimento Rural do Tocantins (Ruraltins), Associações e técnicos voluntários da comunidade visando a melhorar o cultivo da terra e a produção dos agricultores; (iv) aprendizado de técnicas naturais (práticas e fáceis) de controle de insetos/pragas, evitando assim o uso de agrotóxicos (produtos que trazem risco de contaminações do meio ambiente e dos agricultores); v) produção de alimentos saudáveis e livres de contaminação; (vi) conhecimento de programas $\left(\mathrm{PAA}^{23}\right.$ e $\mathrm{PNAE}^{24}$ ) do Governo que garantem a aquisição de alimentos produzidos pelas famílias dos pequenos agricultores.

23. O Programa de Aquisição de Alimentos (PAA) foi criado em 2003 e é uma ação do Governo Federal para colaborar com o enfrentamento da fome e da pobreza no Brasil e, ao mesmo tempo, fortalecer a agricultura familiar.

24. O Programa Nacional de Alimentação Escolar (PNAE) foi implantado pelo Fundo Nacional de Desenvolvimento da Educação (FNDE) em 1995. De acordo com a Lei n ${ }^{0} 11.947$, de 16 de junbo de 2009, no mínimo 30\% do valor repassado pelo PNAE a estados, municípios e Distrito Federal pelo FNDE devem ser aplicados na aquisição de produtos alimentícios "diretamente da agricultura familiar e do empreendedor familiar rural ou de suas organizações, priorizando-se os assentamentos da reforma agrária, as comunidades tradicionais indígenas e as comunidades quilombolas. A aquisição dos 
Portanto, podemos destacar aqui que, talvez, antes de estudar o tema do $P E$ Agricultura familiar Leomar e a maioria dos colegas da turma não tivessem conhecimento acerca de cultivo orgânico, controle de pragas com produtos naturais e dos programas que garantem aos camponeses o direito de vender sua produção a um preço "justo". Entendemos que, ao desenvolver esse tema do PE, a escola-campo reforça que a formação alicerçada pelos princípios da alternância não visa apenas ao desenvolvimento do letramento escolar entre os alunos que ali estudam, mas sobretudo preparar os jovens de modo que possam ser multiplicadores dos conhecimentos aprendidos na escola dentro das comunidades. Certamente, tais práticas trazem aspectos do letramento ideológico, que é fortalecer os estudantes como atores sociais.

\subsection{Intervenção Externa}

As Intervenções externas, no contexto de ensino da PA, são um IP importante para ampliação ou aprofundamento do conhecimento dos estudantes em formação a respeito do tema de um PE em estudo, além de possibilitar trocas de experiências com outros atores sociais (COLINAS, 2015). Por isso, essas atividades são realizadas em forma de exposição ou debate, tendo como colaborador um parceiro externo, como agricultores, pais, mães de estudantes, técnicos, profissionais que tenham experiência com tal tema e algo a contribuir com a formação pessoal/profissional dos alternantes. E os relatos produzidos durante tal ação pelos estudantes serão registrados em seção específica do CR (SILVA, 2011).

Para realizar a etapa Intervenção externa, por ocasião dos estudos do tema do PE Agricultura familiar, a escola-campo convidou um profissional do escritório local do Serviço Brasileiro de Apoio às Micro e Pequenas Empresas (SEBRAE), que é Técnico em Agropecuária e nessa empresa presta assistência na área rural, para ministrar uma palestra para a turma colaboradora a respeito do tema, conforme ilustra a seção Intervenção externa do CR de uma colaboradora (Nelma) da nossa pesquisa na Figura 3:

produtos da Agricultura Familiar poderá ser realizada por meio da Chamada Pública, dispensandose, nesse caso, o procedimento licitatório". Disponível em: < http://www.fnde.gov.br/programas/ alimentacao-escolar/agricultura-familiar> acesso em: 23 jun. 2017. 


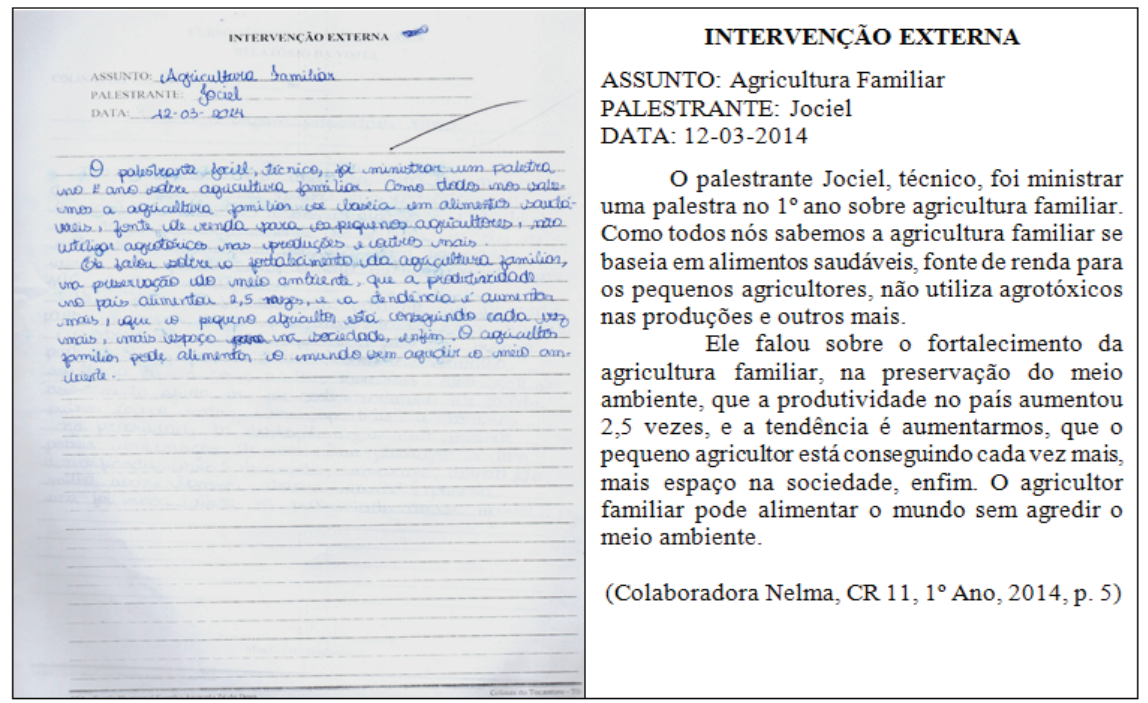

Figura 3. Intervenção externa - PE Agricultura familiar - Registro no CR

$\mathrm{Na}$ PA, a Intervenção externa, além de constituir um IP importante e que favorece a "abertura" das portas da escola para que outros atores da comunidade possam contribuir para ampliação do conhecimento dos estudantes a respeito de certas temáticas, torna-se um espaço fundamental de interações entre a instituição de ensino (CEFFA) e instituições parceiras da escola, bem como entre monitores/ alunos e parceiros colaboradores. Certamente, tal articulação fortalece a unidade de ensino e a formação dos estudantes.

Na Figura 3, o relato da colaboradora Nelma acerca da palestra de um colaborador a respeito do PE Agricultura familiar destaca basicamente três pontos importantes: (i) a agricultura familiar produz alimentos saudáveis (livres de agrotóxicos); (ii) a agricultura familiar exige uma consciência por parte das pessoas no tocante à preservação ambiental, ou seja, o homem pode produzir, mas em harmonia com o meio ambiente; (iii) a agricultura familiar apresenta perspectivas de fortalecimento e crescimento econômico.

Embora o técnico tenha abordado na palestra outros aspectos da agricultura familiar no Brasil, depreendemos que os três pontos destacados pela colaboradora no texto da Figura 3 refletem questões importantes que ela apreendeu e mirou sob a ótica da realidade local em que vive. Com base nos conhecimentos adquiridos, além de tal aluna representar uma (futura) agente em potencial dentro da comunidade local em defesa da preservação do meio ambiente, pode ainda ajudar a conscientizar 
as pessoas quanto aos perigos ou riscos que o uso de agrotóxicos na produção de alimentos oferece à saúde humana. Conforme o ponto três, o fortalecimento e crescimento da agricultura familiar são destacados pela colaboradora como um dado importante para o futuro dos camponeses, o que nos leva a afirmar que é um fator capaz de ajudar a assegurar a permanência do homem no campo.

Outros aspectos da Figura 3 também chamam a atenção, dependendo do que o estudante fará com esse relato em que focaliza a Intervenção externa ou mesmo em relação à formação esperada para os jovens. Podemos afirmar que o monitor poderia ter contribuído um pouco mais com o aluno no sentido de leválo a refletir sobre o próprio texto e ampliar a reflexão. Embora não apareça na Figura 3, o formador poderia ter apresentado intervenções/sugestões (em forma de comentários escritos no próprio texto) para que o estudante pudesse ampliar o (conteúdo) texto. Dessa forma, as práticas de uso da linguagem escrita podem favorecer e fortalecer o letramento local, uma vez que possibilita ao aluno ampliar o conhecimento e conquistar autonomia no processo formativo. Para finalizar nossa análise, apresentamos a seguir a última seção, denominada Visita de estudo.

\subsection{Visita de Estudo}

Na PA, a Visita de estudo é um Instrumento Pedagógico importante que se concretiza com o deslocamento de uma turma ou grupo de alunos, guiados por um agente de letramento (monitor) do CEFFA, para visitar e conhecer uma experiência concreta (extraescola) na comunidade. Para tanto, há um roteiro pré-estabelecido pelo monitor responsável pela visita de estudo, a fim de orientar os estudantes a aprofundarem os conhecimentos a respeito do tema em estudo de um PE e comparar às práticas e conhecimentos individuais (SILVA, 2011).

Para corroborar parte das Práticas escolares externas (cf. Quadro 3), ilustramos a seguir um registro fotográfico e excerto de um Diário de campo da nossa pesquisa relacionados à Visita de estudo acerca do tema do PE Agricultura familiar: 


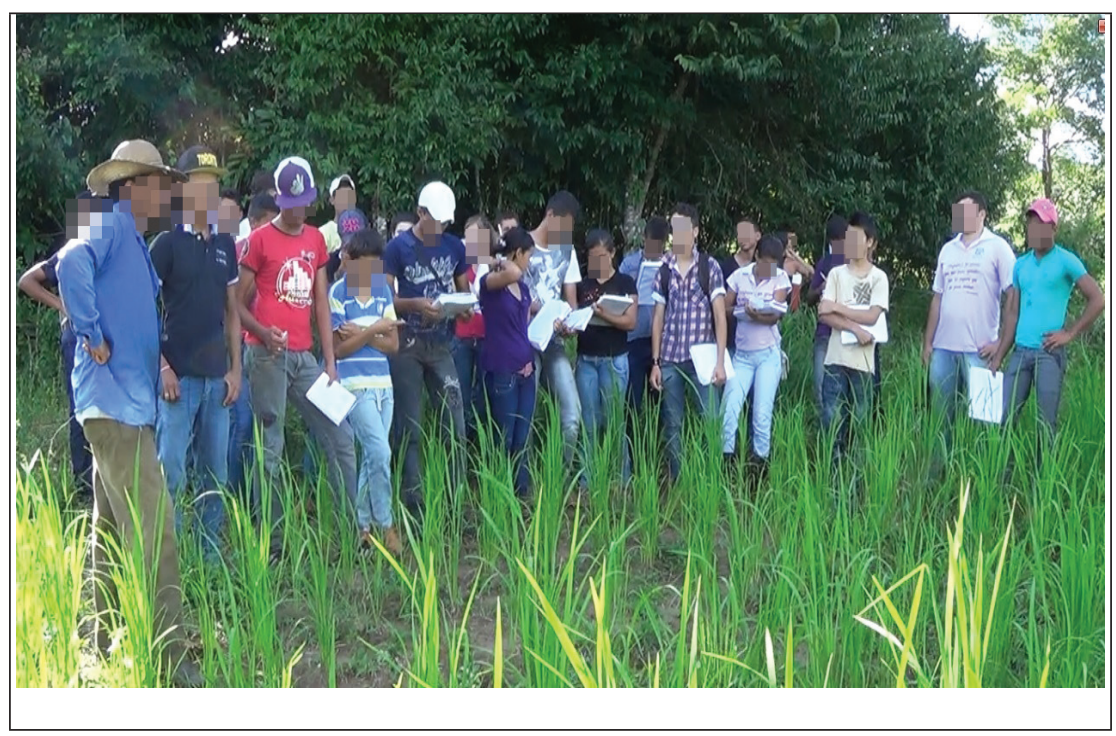

Figura 4. Visita de estudo - PE Agricultura familiar ${ }^{25}$

Fonte: Pesquisa do autor (2014).

A Figura 4 ilustra os estudantes com caderno e caneta nas mãos, sendo que alguns estão tomando nota. A imagem também mostra, do lado esquerdo (de camisa azul e chapéu), o Senhor "Pedro" (agricultor) posicionado à frente do grupo de jovens dentro de sua plantação de arroz. Estes estão entrevistando-o. Conforme as Práticas escolares externas delineadas no Quadro 3, a proposta formativa da Pedagogia da Alternância é responsável por instaurar muitas práticas de letramento, a exemplo das situações de interação apresentadas na figura (4): (i) Os estudantes estão realizando Entrevista oral com um camponês/agricultor; (ii) Alguns realizam a Leitura do script/ questionário Pesquisa do $P E_{\text {; }}$ (iii) Outros deles efetuam Tomada de notas durante entrevista; (iv) a turma está realizando Visita de estudo sobre tema do PE (in loco). Evidentemente, esse tipo de atividade promovida pelo CEFFA cria condições para que os jovens apropriem de saberes não só por meio da teoria, mas pela práxis, o que contempla os letramentos situados. Por outro lado, graças à opção pela observação participante na pesquisa pudemos fazer os registros da atividade.

Outro tipo de registro importante da pesquisa etnográfica e que foi gerado em grande quantidade durante nosso estudo são os diários de campo ou notas de campo. As notas de campo "são uma forma de representação, isto é, uma forma de reduzir

25. A foto mostra a visita dos estudantes a uma pequena propriedade, situada no meio rural. A visita faz parte das atividades de estudo sobre o tema do PE Agricultura familiar. 
eventos apenas observados, pessoas e lugares para relatos escritos"26 (EMERSON et al., 2001 apud MASON, 2002, p. 98). Como acompanhamos diferentes momentos das atividades realizadas no Tempo Comunidade a respeito dos temas do PE, nossos diários de campo foram produzidos concomitantemente aos eventos, experiências e interações dos atores sociais. Eles incorporam nossas percepções, interpretações do cotidiano, experiências do ambiente da pesquisa. Foram elaborados contemplando descrições minuciosas dos fatos, espaços ou atividades envolvendo os colaboradores, nossas impressões, ideias e conjeturas.

Por ter sido produzido durante a pesquisa de campo e narrar a mesma visita de estudo registrada na Figura 4, o seguinte excerto do pesquisador enfatiza a importância dos estudos dos PE para o letramento dos jovens:

Exemplo 03 - Visita de estudo

Durante a visita, os alunos conheceram plantações de arroz, milho, abóbora, uma horta, criação de galinhas e suínos. Enquanto o Sr. "Pedro" estava mostrando suas plantações e animais, os estudantes faziam perguntas relacionadas ao cultivo, manejo, destino da produção, produtividade, dificuldades enfrentadas pelo camponês, dentre outros aspectos. Em alguns momentos, o monitor Décio também explicou, como por exemplo, a importância da rotatividade de cultura para 'descansar' o solo. Por sua vez, os jovens tomavam notas em seus cadernos. (PE Agricultura familiar: Visita de estudo. Diário de Campo. N. 005/2014).

Segundo a proposta de execução ou "aplicação" de um PE na PA, o jovem poderá ampliar seus conhecimentos em relação ao assunto e aplicá-los posteriormente na sua vida cotidiana. A PA é um sistema educativo diferenciado, cuja proposta formativa dialoga com os saberes contextualizados. E esse diálogo pode ser visualizado nas diferentes atividades ou etapas de estudos dos temas dos PE, fazendo com que conteúdos e contexto se imbriquem. Por outro lado, nossas análises também sinalizam o caminho percorrido e a realidade do ensino na perspectiva da alternância para atender parte das demandas da Educação do Campo e que, por sinal, são muitas. Ao promover a inserção de temas vinculados à realidade do campo no Plano de Formação do CEFFA, a PA proporciona aos jovens camponeses a possibilidade de conectar suas vivências sociais, culturais e produtivas à construção do conhecimento, experenciadas em sala de aula, na propriedade da família e na comunidade. Tudo isso promove práticas e ações reflexivas, as quais podem ser visualizadas nos dados de pesquisa apresentados, sejam eles orais ou

26. Do original em Inglês: "Fieldnotes are a form of representation, that is, a way of reducing just-observed events, persons and places to written accounts" (MASON, 2002, p. 98). 
escritos. E, para conhecer as práticas de letramentos do sistema educativo da alternância, as contribuições da etnografia foram essenciais.

\section{CONSIDERAÇÕES FINAIS}

Considerando a realidade das práticas didático-pedagógicas do sistema educativo da Pedagogia da Alternância (PA), mais especificamente o desenvolvimento dos estudos dos temas geradores dos Planos de Estudo (PE) em uma turma do $1^{\circ}$ ano do Ensino Médio de uma EFA, a pesquisa corrobora que a etnografia oferece subsídios capazes de nos permitir abrir a "caixa preta" da alternância e conhecermos o que é um Plano de Formação, os Planos de Estudo, a Pesquisa do PE, a Colocação em comum, a Visita de estudo, a Intervenção interna, o Caderno da Realidade, entre outros Instrumentos Pedagógicos adotados em um CEFFA.

No caso das contribuições proporcionadas aos estudantes, podemos citar a produção do Caderno da Realidade, cujos registros escritos exigem dos alunos tanto leitura quanto reflexão a respeito da língua para produção dos diferentes gêneros discursivos que são específicos do contexto da PA. Além disso, tais gêneros emergem de práticas e eventos de letramento situados em contextos de uso da linguagem (escola, família, comunidade), dos quais os jovens participam nas interações (orais e escritas) para produção de seus textos.

Os resultados da investigação também apontam que as práticas e eventos de letramento evidenciados na pesquisa transcendem aquilo que a escola conservadora propõe a ensinar em termos de letramento; não é uma formação reduzida à escrita por si mesma. Além da interação com o monitor (formador), os estudantes também interagem com os atores sociais da comunidade local, reforçando que a formação proposta pela PA nos CEFFA não se limita ao desenvolvimento apenas do letramento autônomo. Apesar de o método observacional ser difícil e desafiador para o pesquisador, a etnografia foi muito importante para o desenvolvimento da pesquisa de campo.

\section{REFERÊNCIAS BIBLIOGRÁFICAS}

ANDRÉ, M. E. D. A. (2012). Etnografia da prática escolar. 18 ed. Campinas: Papirus.

ANGROSINO, M. (2009). Etnografia e observação participante. Porto Alegre: Artmed/ Bookman. 
BAKHTIN, M. (2006). Os gêneros do discurso. In: BAKHTIN, M. Estética da criação verbal. 4. ed. São Paulo: Martins Fontes, pp. 261-335.

BARTON, D.; HAMILTON, M. (2012). Local literacies: reading and writing in one community. London/New York: Routledge.

BARTON, D.; PAPEN, U. (2010). What is the Anthropology of writing? In: BARTON, D.; PAPEN, U. The Antbropology of writing: understanding textually-mediated worlds. London/New York: Continuum, pp. 3-32.

BRONCKART, J.-P. (2009). Atividade de linguagem, textos e discursos: por um interacionismo sociodiscursivo. 2. ed. São Paulo: EDUC.

CALDART, R. S. (2002). Por uma Educação do Campo: traços de uma identidade em construção. In: KOLliNG, E. J.; CERIOLE, P. R.; CALDART, R. S. (Orgs.). Educação do Campo: identidade e políticas públicas. Brasília: articulação nacional por uma Educação do Campo, pp. 18-25.

CANCLINI, N. G. (2013). Culturas bíbridas: estratégias para entrar e sair da modernidade. 4. ed. São Paulo: EdUSP.

CHEVALLARD, Y. (1991 [1985]). La transposition didactique: du savoir savant au savoir enseigné. Paris: La Fenseé Sauvage.

COLINAS. (2015). Projeto Pedagógico da Escola Municipal Família Agrícola Zé de Deus de Colinas do Tocantins-TO. Colinas do Tocantins: s/n. (mimeo)

DENZIN, N. K.; LINCOLN, Y. S. (2006). Introdução: a disciplina e a prática da pesquisa qualitativa. In: DENZIN, N. K.; LINCOLN, Y. S. O planejamento da pesquisa qualitativa: teorias e abordagens. 2. ed. Porto Alegre: Artmed/ Bookman, pp. 15-41.

ERICKSON, F. (1986). Qualitative methods in research on teaching. In: WITTROCK, M. C. (org.). Handbook of research on teaching. 3 ed. New York: Macmillan, pp. 119-161.

GARCEZ, P. M.; BULlA, G. da S.; LODER, L. L. (2014). Práticas de pesquisa microetnográfica: geração, segmentação e transcrição de dados audiovisuais como procedimentos analíticos plenos. D.E.L.T.A. v. 30, n. 2, pp. 257-288.

GIMONET, J.-C. (2007). Praticar e compreender a Pedagogia da Alternância dos CEFFAs. Petrópolis: Vozes; Paris: AIMFR. 
GIMONET, J.-C. (1998). L'Alternance en Formation. 'Méthode Pédagogique ou nouveau système éducatif?' L'experiénce des Maisons Familiales Rurales. In: DEMOL, J.N.; PILON, J.-M. (Orgs.). Alternance, developpement personnel et local. Trad. Thierry de Burghgrave. Paris: L’Harmattan, pp. 51-66.

KLEIMAN, A. B. (2014). Letramento na contemporaneidade. Bakbtiniana. v. 9, n. 2, pp. 72-91.

MASON, J. (2002). Qualitative researching. 2. ed. London: Sage Publications.

NOSELLA, P. (2014). Origens da Pedagogia da Alternância no Brasil. Vitória: EDUFES.

OLIVEIRA, M. A. A. (2013). O Ensino de Lingua Portuguesa: usos do livro didático, objetos de ensino e gestos profissionais. 407f. Tese (Doutorado em Linguística Aplicada). Universidade Estadual de Campinas, Campinas.

SIGNORINI, I. (Org.). (2006). Gêneros catalisadores: letramento e formação de professor. São Paulo: Parábola Editorial.

SILVA, C. (2018). Pedagogia da Alternância: práticas de letramentos em uma Escola Família Agrícola Brasileira. 232f. Tese (Doutorado em Letras). Universidade Federal do Tocantins, Araguaína.

SILVA, C. (2014). Caderno da Realidade na Pedagogia da Alternância: um instrumento pedagógico mediador do letramento. 18f. Universidade Federal do Tocantins, Araguaína. (Inédito).

SILVA, C. (2011). Pedagogia da Alternância: um estudo do gênero Caderno da Realidade com foco na retextualização. 149f. Dissertação (Mestrado em Letras). Universidade Federal do Tocantins, Araguaína.

SILVA, C.; ANDRADE, K. S.; MOREIRA, F. (2015). A retextualização no gênero Caderno da Realidade na Pedagogia da Alternância. Acta Scientiarum. Language and Culture. v. 37, n. 4, pp. 359-369.

STREET, B. (2014). Letramentos sociais: abordagens críticas do letramento no desenvolvimento, na etnografia e na educação. Tradução Marcos Bagno. São Paulo: Parábola Editorial.

Recebido: 22/11/2017

Aceito: $25 / 02 / 2018$ 